\title{
Vitamin A absorption and metabolism in the chick: response to high dietary intake and to tocopherol
}

\author{
BY DAVID SKLAN \\ Faculty of Agriculture, The Hebrew University of Jerusalem, PO Box 12, \\ Rehovot 76-100, Israel
}

(Received 17 May 1982 - Accepted 15 April 1983)

\begin{abstract}
1. Absorption of ${ }^{14} \mathrm{C}$-labelled retinol was determined along the gastrointestinal tract of chicks, using ${ }^{141} \mathrm{Cerium}$ as a non-absorbed reference substance, as influenced by high dietary vitamin $A$ and the addition of tocopherol to the diet.

2. The site of major vitamin A absorption was the proximal small intestine and high intake of vitamin $\mathbf{A}$ reduced slightly the percentage over-all absorption.

3. Labelled glucuronides were secreted into the duodenum and were $50-60 \%$ reabsorbed in the small intestines. High-vitamin-A intakes enhanced the duodenal flow of retinyl glucuronides.

4. In vitro hepatic retinol esterification and glucuronide production were enhanced in chicks given high dietary vitamin A.

5. Plasma transport and clearance of retinol were enhanced by feeding high levels of vitamin $A$ and further enhanced when tocopherol at high concentrations was present in the diet.

6. Dietary tocopherol had no effect on absorption, increased hepatic vitamin A stores and in vitro retinol esterification, and decreased retinyl glucuronide flows through the duodenum.
\end{abstract}

Dietary vitamin A is converted to retinol before absorption from the intestinal lumen and is transported as retinyl esters in chylomicrons to the liver (Huang \& Goodman, 1965). The liver plays a major role in vitamin A homeostasis, acting as the major vitamin A storage organ, and regulates the output of retinol to tissues bound to retinol-binding protein (Muhilal \& Glover, 1974; Smith \& Goodman, 1979). Following high intakes of vitamin A, liver storage capacity may become saturated and levels of retinyl esters in plasma, normally low, increase and symptoms of hypervitaminosis A appear at approximately this time (Mallia et al. 1975; Donoghue et al. 1981). Additional regulatory mechanisms for attenuating high-vitamin-A intake have not been delineated, although vitamin $\mathrm{A}$ status appears to influence plasma retinol turnover (Varma \& Beaton, 1972; Lewis et al. 1981; Donoghue et al. 1983).

One catabolic route of retinol involves conversion to glucuronides by hepatic microsomes (Lippel \& Olson, 1968) and secretion via the bile to the intestine, where some recirculation occurs (Nath \& Olson, 1967; Hume et al. 1971). It is not clear to date, if this pathway is enhanced on high-retinol intakes.

Addition of tocopherol to high-vitamin-A diets has been reported to alleviate the hypervitaminosis A syndrome (Cawthorne et al. 1968; Jenkins \& Mitchell, 1975; Sondergaard, 1972) and also enhances the enterohepatic tocopheryl glucuronide secretion (Sklan \& Donoghue, 1982).

The objective of this study was to examine vitamin A absorption, enterohepatic circulation and homeostasis at normal and high dietary levels, and to determine the response to additional dietary tocopherol. 


\section{EXPERIMENTAL}

\section{Materials}

Hoffman-LaRoche, Basel, provided the $\left[15-{ }^{14} \mathrm{C}\right] \mathrm{retinol}(5 \cdot 5 \mu \mathrm{Ci} / \mathrm{mg}) ;{ }^{141} \mathrm{Ce}$ was obtained from Amersham International, Amersham, Bucks and $\beta$-glucuronidase (EC 3.2.1.31) from Sigma Chemical Co., St Louis, MO.

New Hampshire $\times$ Leghorn male chicks were given a diet containing $(\mathrm{g} / \mathrm{kg}): 608$ sorghum, 323 soya-bean meal, 30 soya-bean oil (Sklan \& Donoghue, 1982) for $21 \mathrm{~d}$ from hatching, to which retinyl acetate and $\mathrm{D}-\alpha$-tocopheryl acetate were added as follows: control diet, $10 \mathrm{mg}$ tocopheryl acetate $/ \mathrm{kg}, 850 \mu \mathrm{g}$ retinyl acetate $/ \mathrm{kg}$; diet E, $200 \mathrm{mg}$ tocopheryl acetate $/ \mathrm{kg}, 850 \mu \mathrm{g}$ retinyl acetate $/ \mathrm{kg}$; diet $\mathrm{A}, 10 \mathrm{mg}$ tocopheryl acetate $/ \mathrm{kg}, 350000 \mu \mathrm{g}$ retinyl acetate $/ \mathrm{kg}$; diet $\mathrm{A}+\mathrm{E}, 200 \mathrm{mg}$ tocopheryl acetate $/ \mathrm{kg}, 350000 \mu \mathrm{g}$ retinyl acetate $/ \mathrm{kg}$.

\section{Expt 1}

After $21 \mathrm{~d}$ on the diets described previously chicks received a bolus of $8 \mu \mathrm{Ci}{ }^{14} \mathrm{C}$-labelled retinol in $0.2 \mathrm{ml}$ saline $(9 \mathrm{~g}$ sodium chloride/1) containing (/1) $10 \mathrm{ml}$ Tween 80 and $200 \mathrm{ml}$ ethanol. Blood samples were obtained after 6, 12, 24, 30, 48, 72 and $96 \mathrm{~h}$. Plasma was extracted and the concentration of retinol, retinyl esters (Neeld \& Pearson, 1963) and radioactivity was determined after alumina chromatography (Harrison et al. 1979).

\section{Expt 2}

Chicks were given the rations for $21 \mathrm{~d}$ and then transferred to the same diets to which had been added $(/ \mathrm{kg}) 50 \mu \mathrm{Ci}{ }^{14} \mathrm{C}$-labelled retinyl acetate and $50 \mu \mathrm{Ci}{ }^{141} \mathrm{Ce}$ as a non-absorbed reference substance. After $4 \mathrm{~d}$ on this diet chicks were killed with an intracardiac overdose of sodium pentothal and the contents of five intestinal segments removed as previously described (Sklan et al. 1975a). Livers were also removed and stored at $-20^{\circ}$ under nitrogen until analysis.

Intestinal contents were homogenized using a high-speed homgenizer and portions taken for ${ }^{141} \mathrm{Ce}$ determination by $\gamma$-scintillation. One portion was extracted with chloroformmethanol (Folch et al. 1957) and an additional portion treated with 100 units $\beta$-glucuronidase at pH 7.4 (Lippell \& Olson, 1968) and incubated for $90 \mathrm{~min}$ at $37^{\circ}$ before chloroformmethanol extraction.

The chloroform was evaporated under $\mathrm{N}_{2}$, retinyl esters and retinol separated by alumina chromatography and portions taken for measurement of radioactivity by liquid scintillation spectrophotometry and retinol determination as described previously. Livers were homogenized, extracted and retinol and retinyl esters separated in a similar fashion.

\section{In vitro experiments}

Chicks were given the diets described previously for $24 \mathrm{~d}$ and killed with an intracardiac overdose of sodium pentothal. Livers were removed and homogenized with $0.25 \mathrm{M}$-sucrose $(1: 3, \mathrm{w} / \mathrm{v})$ containing $0.1 \mathrm{M}$-potassium chloride and approximately $20 \mathrm{mg}$ protein were incubated with $0.02 \mu \mathrm{Ci}{ }^{14} \mathrm{C}$-labelled retinol, $10 \mu \mathrm{mol}$ ATP, $2 \mu \mathrm{mol}$ coenzyme A, $2 \mu \mathrm{mol}$

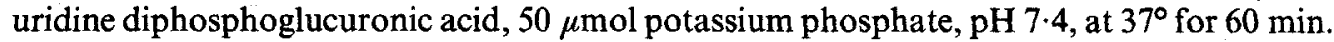
At the end of this period, samples were extracted and treated as described previously and retinyl esters, retinol and retinyl glucuronides separated and radioactivity counted.

\section{Calculations}

Transport and clearance rates of plasma vitamin A were calculated from the area under the specific activity $v$. time curve as previously described (Donoghue et al. 1979).

When a non-absorbed reference substance is fed until a steady-state with regard to 
Table 1. Logarithms of concentrations of vitamin $A$ in the plasma and livers of chicks given the experimental diets*

(Mean values and standard deviations for six chicks per treatment; values in parentheses indicate percentage retinyl esters in plasma. Two factor analysis of variance was used to determine the significance of vitamin $A(A)$, tocopherol $(E)$ ahd the interaction $(A+E)$ )

\begin{tabular}{|c|c|c|c|c|c|c|c|c|c|}
\hline \multirow[t]{2}{*}{ Diet... } & \multicolumn{2}{|c|}{ Control } & \multicolumn{2}{|c|}{$\mathbf{E}$} & \multicolumn{2}{|c|}{ A } & \multicolumn{2}{|c|}{$A+E$} & \multirow[b]{2}{*}{$P<0.05$} \\
\hline & Mean & SD & Mean & SD & Mean & SD & Mean & SD & \\
\hline Plasma $(\log \mu \mathrm{g} / 1)$ & \multicolumn{2}{|c|}{$2.47{ }_{(5.3)}^{0.03}$} & \multicolumn{2}{|c|}{${ }_{(4.7)} .04$} & \multicolumn{2}{|c|}{$\begin{array}{c}2.83 \underset{(40.5)}{0.03} \\
\end{array}$} & \multicolumn{2}{|c|}{ 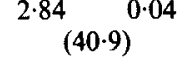 } & $A, E, A+E$ \\
\hline Liver $(\log \mu \mathrm{g} / \mathrm{g})$ & $1 \cdot 70$ & 0.02 & 1.75 & 0.04 & $3 \cdot 41$ & 0.05 & $3 \cdot 62$ & 0.03 & $\mathrm{~A}, \mathrm{E}, \mathrm{A}+\mathrm{E}$ \\
\hline
\end{tabular}

* For details of diets, see p. 402 .

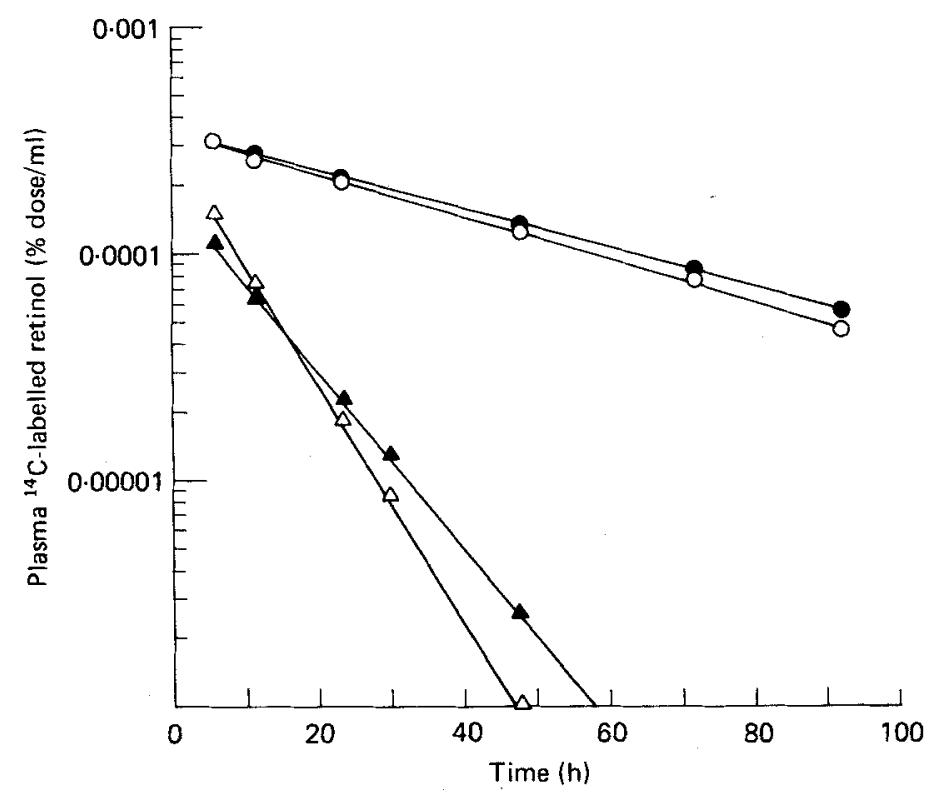

Fig. 1. Amounts of labelled retinol in plasma over $96 \mathrm{~h}$ in control $(O), \mathrm{E}-(\mathrm{O}), \mathrm{A}-(\triangle)$ and $A+E-(A)$ treated chicks (for details of diets, see p. 402). Lines represent the following equations: Control, $Y=0.000345 \mathrm{e}^{-0.0212 t} ; \mathrm{E}, \quad Y=0.000340 \mathrm{e}^{-0.0185 t} ; \mathrm{A}, \quad Y=0.000303 \mathrm{e}^{-0.1197 t}$; $\mathrm{A}+\mathrm{E}, Y=0.000189^{-0.0887 t}$; where $Y$ is the $\%$ dose $/ \mathrm{ml}$ and $t$ is the time (h). $F$ tests showed that all lines were significant $(P<0.01)$.

input-output of marker is obtained, the ratio between any dietary component and marker can be used to calculate net changes between different sites. A decrease in the ratio between two points represents disappearance (including absorption and metabolism) and an increase represents formation or net secretion. Daily flows can be calculated by multiplying the ratio at any point by the daily intake of the reference substance. If the specific activity of the feed is the same as the specific activity of the body, then division of the retinol counts by the specific activity will give the absolute amounts of retinol. Analysis of variance, two factor analysis of variance, and the multiple range test of Duncan (1955) were used to determine significance of differences between groups. 
Table 2. Plasma transport and clearance rates of retinol in chicks given high and low intakes of vitamin $A$ and tocopherol

(Mean values for six chicks calculated from lines shown in Fig. 1)

\begin{tabular}{lcccccc}
\hline Vitamin A status... & \multicolumn{2}{c}{ Control } & & \multicolumn{2}{c}{ High } \\
\cline { 5 - 6 } Tocopherol status... & Control & High & & Control & High \\
\hline Plasma vitamin A $(\mu \mathrm{g} / \mathrm{l})$ & 298 & 296 & & 676 & 686 \\
Transport $(\mu \mathrm{g} / \mathrm{h})$ & $16 \cdot 8$ & $17 \cdot 1$ & & $255 \cdot 7$ & $319 \cdot 4$ \\
Clearance $(\mathrm{ml} / \mathrm{h})$ & $6 \cdot 2$ & $5 \cdot 7$ & & $383 \cdot 4$ & $469 \cdot 8$ \\
\hline
\end{tabular}

RESULTS

Expt 1

Logarithms of the vitamin A concentrations in the plasma and livers of chicks given the different dietary treatments are shown in Table 1. Plasma total vitamin A levels were slightly affected by the tocopherol in the diet whereas, at high-vitamin-A intakes, plasma vitamin A increased and the percentage of retinyl esters increased from $4-5 \%$ to approximately $40 \%$. Liver vitamin A levels were increased by dietary tocopherol and more so by vitamin A; treatment $\mathrm{A}+\mathrm{E}$ livers had higher vitamin $\mathrm{A}$ than treatment $\mathrm{A}$ livers.

Following a bolus of labelled retinol, the disappearance curves of retinol + retinyl esters from the plasma are shown in Fig. 1 for chicks given high levels of vitamin A; disappearance was rapid and almost complete within $72 \mathrm{~h}$ as compared with control chicks. These curves were fitted to a single exponent and the equations obtained are shown in the legend to Fig. 1. The fit of equations for treatment $A$ and $A+E$ chicks was very good although control and E-treated chicks showed a somewhat poorer fit. These were little improved by using a two-exponent system; all fits were highly significant $(P<0.01)$. The rates of plasma transport and clearance (Table 2) show that the addition of tocopherol to the control diet had no significant effect on rates of transport and clearance. However, the high-vitamin-A intake increased transport approximately fifteen-fold and clearance approximately sixty-fold. The addition of tocopherol to this diet increased both factors by a further $22-25 \%$.

\section{Expt 2}

Chicks were given the control, $\mathrm{A}$ and $\mathrm{A}+\mathrm{E}$ diets containing ${ }^{141} \mathrm{Ce}$ as a non-absorbed reference substance together with ${ }^{14} \mathrm{C}$-labelled retinyl acetate. After $4 \mathrm{~d}$ on the diet, the mean specific activity of vitamin $A$ in feed and liver on all diets was very similar (cpm $/ \mu \mathrm{g}$ ) (control: feed 68423, liver 65680 (SD 5979); A: feed 67.2, liver 70.2 (SD 9.2); A+E: feed 66.5, liver $64 \cdot 1$ (SD 5.3)) and thus flows could be calculated using the specific activity of the feed. Fig. 2 shows absorption of the ${ }^{14} \mathrm{C}$-labelled vitamin along the intestine in the three diets. Major absorption occurred in the duodenum and jejunum in all treatments, with minimal values of ${ }^{14} \mathrm{C}$-labelled vitamin $\mathrm{A}:{ }^{141} \mathrm{Ce}$ observed in the upper ileum. However, in the lower ileum, values of this ratio increased slightly, probably representing net secretion in this segment. No differences were apparent between the treatments in the proximal small intestine and less over-all absorption was found in $\mathrm{A}$ and $\mathrm{A}+\mathrm{E}$ treatments in the lower jejunum and ileum $(P<0.05)$. Control chicks had $50-58 \%$ of retinol + retinyl esters as retinol in the lumen compared with $35-46 \%$ in chicks given the A diet. Calculation of the flows of vitamin A through the gastrointestinal tract are shown in Table 3, together with the glucuronide flows. A and A $+E$ treatments, as expected, exhibited higher flows of vitamin A through both duodenum and ileum than control chicks; percentage absorption was slightly lower in 


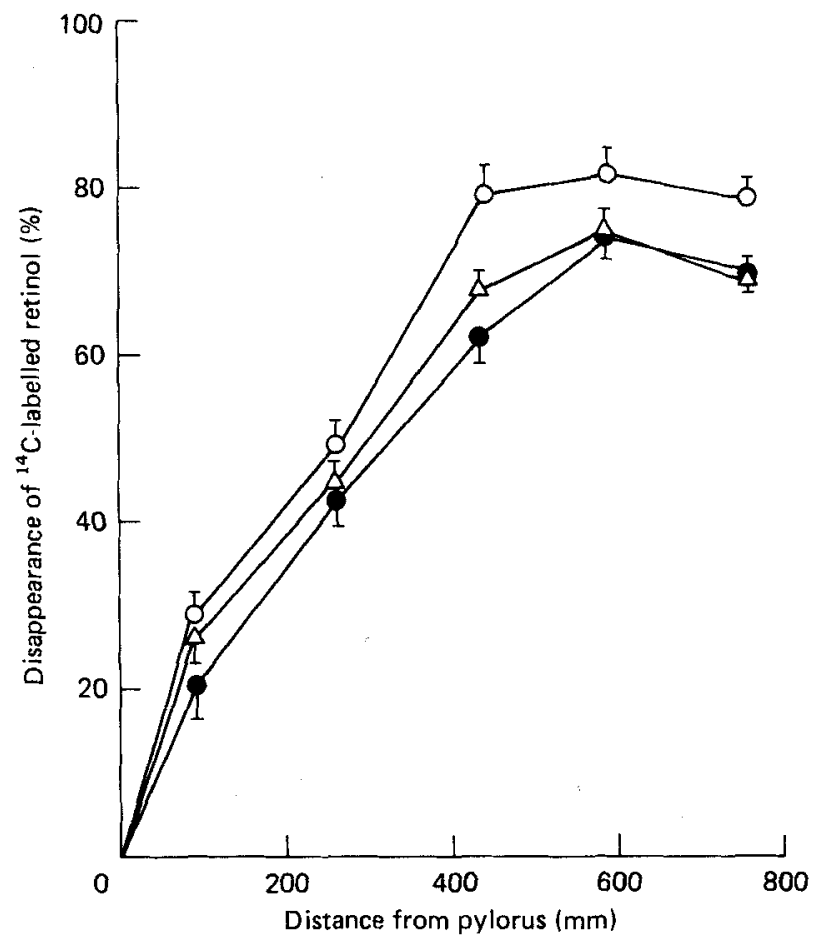

Fig. 2. Percentage intestinal disappearance of ${ }^{14} \mathrm{C}$-labelled retinol with distance from the pylorus in chicks given control $(O), A(\Theta)$ and $A+E(\triangle)$ diets (for details of diets, see p. 402). Points are mean values and standard deviations of results obtained from five chicks. SD are shown where they do not fall within the points shown. The various segments of the intestine correspond to $0-180 \mathrm{~mm}$ duodenum, $190-530 \mathrm{~mm}$ jejunum and $540-850 \mathrm{~mm}$ ileum. Control values differed significantly from $\mathrm{A}$ and $\mathrm{A}+\mathrm{E}$ treatments only in the lower ileum $(P<0.01)$.

Table 3. Daily flows $(\log \mu \mathrm{g} / \mathrm{d})$ of vitamin $A$ and retinyl glucuronides through the intestinal tract of chicks given the experimental diets*

(Mean values and standard deviations of logs of flows for five chicks)

\begin{tabular}{|c|c|c|c|c|c|c|}
\hline \multirow[t]{2}{*}{ Diet... } & \multicolumn{2}{|c|}{ Control } & \multicolumn{2}{|c|}{ A } & \multicolumn{2}{|c|}{$A+E$} \\
\hline & Mean & SD & Mean & SD & Mean & SD \\
\hline Feed vitamin A & 1.44 & & $4 \cdot 40$ & & 4.42 & \\
\hline Duodenal vitamin A & $1 \cdot 35^{a}$ & 0.05 & $4 \cdot 30^{b}$ & 0.08 & $4 \cdot 29^{b}$ & 0.02 \\
\hline Ileal vitamin $\mathrm{A}$ & $0.82^{a}$ & 0.05 & $3 \cdot 88^{b}$ & 0.04 & $3.90^{b}$ & 0.02 \\
\hline Duodenal retinyl glucuronides & $1 \cdot 42^{a}$ & 0.05 & $4 \cdot 54^{b}$ & $0 \cdot 04$ & $4 \cdot 43^{c}$ & 0.02 \\
\hline Ileal retinyl glucuronides & $1 \cdot 11^{a}$ & 0.01 & $4 \cdot 15^{b}$ & 0.03 & $4.09^{c}$ & 0.03 \\
\hline
\end{tabular}

$a, b, c$ Values within the same row not sharing a common superscript letter were significantly different $(P<0.01)$.

* For details of diets, see p. 402.

these treatments. A-fed chicks showed both an absolute and relative increase in fluxes of glucuronides through the duodenum; 1.75-fold for the duodenal vitamin A flux as compared with 1.18 in the control chicks. Both the absolute glucuronide flux and the glucuronide:vitamin A flux values were lower in the A+E-treated chicks than in the A-treated chicks. Glucuronides were $51-60 \%$ recycled and this recycling was highest in the A-treated chicks. 
Table 4. In vitro formation (log $\mu \mathrm{g} / \mathrm{g}$ per $h$ ) of retinyl esters and glucuronides by liver homogenates in chicks given the experimental diets*

(Mean values and standard deviations for six chicks; values in parentheses are specific activities $(\mu \mathrm{g} / \mathrm{h}$ per mg protein))

\begin{tabular}{|c|c|c|c|c|}
\hline \multirow[b]{2}{*}{ Diet } & \multicolumn{2}{|c|}{ Retinyl esters } & \multicolumn{2}{|c|}{ Retinyl glucuronides } \\
\hline & Mean & SD & Mean & SD \\
\hline Control & $1.89^{a}$ & $0.07 \quad(3.5)$ & $1 \cdot 36^{a}$ & $0.06(0.7)$ \\
\hline & $3 \cdot 33^{b}$ & $0.06 \quad(69.6)$ & $1.88^{b}$ & $0.04(2.5)$ \\
\hline$A+E$ & $3.68^{c}$ & $0.04(173.5)$ & $1 \cdot 80^{b}$ & $0.05(2 \cdot 3)$ \\
\hline
\end{tabular}

$a, b, c$ Values within the same column not showing a common superscript letter were significantly different $(P<0.01)$.

* For details of diets, see p. 402 .

\section{Expt 3}

In vitro incubations of liver homogenates with ${ }^{14} \mathrm{C}$-labelled retinol and determination of the formation of both retinyl esters and retinyl glucuronides were carried out (Table 4). Retinyl ester formation was enhanced in A-treated chicks and further enhanced in A +E-treated chicks. Glucuronide production was enhanced, compared with controls, in both A- and A+E-treated chicks with no higher production in the A-fed birds. Specific enzyme activities showed similar trends.

\section{DISCUSSION}

The site of absorption of vitamin A in the chicks has been shown in this study, using a non-absorbed reference substance, to be the proximal small intestine. This is parallel to the site of absorption of fatty acids and cholesterol in the chick (Sklan et al. 1973, 1975b). Absorption of vitamin A was essentially complete by the upper ileum and a small increase in the ${ }^{14} \mathrm{C}$-labelled vitamin $\mathrm{A}:{ }^{141} \mathrm{Ce}$ value was observed between the upper and lower ileum. This indicates net secretion; thus the serosal-mucosal retinol flux was greater than the mucosal-serosal flux. A similar trend was obtained with labelled cholesterol in the chick ileum (Sklan et al. 1977).

An enterohepatic circulation of retinyl glucuronides was demonstrated in the chick as previously reported in the rat (Nath \& Olson, 1967) and in sheep (Hume et al. 1971). This circulation has also been quantified in the chick and is of the same order of magnitude as the vitamin A intake. Approximately $50-60 \%$ of the duodenal glucuronide secretion was reabsorbed along the gastrointestinal tract.

Increasing the vitamin A intake did not alter the site of absorption although the over-all percentage absorption was somewhat decreased $(P<0.01)$ and more esterified retinol was found in the intestinal lumen. Glucuronide secretion was also increased by the high dietary vitamin $\mathrm{A}$ intake and this increase was proportionally somewhat greater than the increase in dietary level. In vitro glucuronide production from retinol was enhanced in liver homogenates from chicks given the high-vitamin-A diets and retinol esterification was also enhanced. The excretion of glucuronides through the ileum was also increased in chicks on the high-vitamin-A diets and this represents an output from the body.

Feeding the high levels of vitamin $A$ enhanced both plasma transport and clearance of vitamin $\mathrm{A}$; the plasma disappearance curve of $\mathrm{A}$ - and $\mathrm{A}+\mathrm{E}$-treated chicks could be well represented by a single exponent. Control vitamin A chicks showed a slightly poorer fit (although still highly significant) and a two-exponential model resulted in only a small 
improvement in $R^{2}$. Lewis et al. (1981) used a three-pool model in the rat and Donoghue et al. (1983) used three or four exponentials to fit plasma vitamin A disappearance in the sheep. It is probable that more samples are required, especially close to the injection time, to describe fully a kinetic model in the chick.

Addition of both vitamin $\mathrm{A}$ and tocopherol to the diet increased hepatic vitamin $\mathrm{A}$ levels as has been previously reported (Cawthorne et al. 1968; Sondergaard, 1972; Jenkins \& Mitchell, 1975). No differences in absorption between A- and A+E-fed chicks were noted, whereas plasma transport and clearance of vitamin A was enhanced in A + E-treated chicks. Liver homogenates in $\mathrm{A}+\mathrm{E}$-fed chicks showed enhanced in vitro esterification as compared with A-fed chicks, but no difference in in vitro glucuronide production was obtained. The glucuronide flow measurements showed less retinyl glucuronide secretion to the duodenum and from the ileum in A+E-treated chicks than in A-treated chicks. The observations together may explain the higher hepatic vitamin A levels in A+E-treated chicks.

Lipell \& Olson (1968) have described the synthesis of glucuronides by liver microsomes as occurring together with esterification and it has been recently demonstrated that increasing dietary tocopherol increases the production of tocopheryl glucuronides (Sklan \& Donoghue, 1982). It is thus possible that the substrates or enzymes for glucuronide synthesis are limiting in $\mathrm{A}+\mathrm{E}$-treated livers and thus, as retinyl glucuronide formation decreases, esterification of retinol increases.

Vitamin A status has been shown to affect vitamin A turnover in the rat (Varma \& Beaton, 1972; Lewis et al. 1981) and in the sheep (Donoghue $e t$ al. 1983) and urinary and faecal pathways of homeostasis have been proposed. This study provides additional evidence for the presence of homeostatic pathway of retinol catabolism and excretion via glucuronides in the chick.

This study was supported by a grant from the Leonard Wolfson Foundation, The Hebrew University. Skilled technical assistance was by Mrs O. Kedar, and Dr Y. Hillel advised on the statistical analyses. ${ }^{14} \mathrm{C}$-labelled retinol was a kind gift of Hoffman-LaRoche, Basel.

\section{REFERENCES}

Cawthorne, M. A., Bunyan, J., Diplock, A. T., Murrell, E. A. \& Greenm, J. (1968). British Journal of Nutrition 22, 133-140.

Donoghue, S., Kronfeld, D. S., Berkowitz, S. J. \& Copp, R. L. (1981). Journal of Nutrition 111, 365-370.

Donoghue, S., Kronfeld, D. S. \& Ramberg, C. F. (1979). Journal of Dairy Science 62, 326-332.

Donoghue, S., Kronfeld, D. S. \& Sklan, D. (1983). British Journal of Nutrition 50, 235-248.

Duncan, D. B. (1955). Biometrics 11, 1-42.

Folch, J., Lees, M. \& Stanley, G. H. S. (1957). Journal of Biological Chemistry 226, 497-509.

Harrison, E. H., Smith, J. E. \& Goodman, D. S. (1979). Journal of Lipid Research 20, 760-771.

Huang, H. S. \& Goodman, D. S. (1965). Journal of Biological Chemistry 240, 1169-1176.

Hume, I. D., Mitchell, G. E. \& Tucker, R. E. (1971). Journal of Nutrition 101, 1169-1176.

Jenkins, M. Y. \& Mitchell, G. V. (1975). Journal of Nutrition 105, 1600-1606.

Lewis, K. C., Green, M. H. \& Underwood, B. A. (1981). Journal of Nutrition 111, 1135-1144.

Lippell, K. \& Olson, J. A. (1968). Journal of Lipid Research 9, 168-175.

Mallia, A. K., Smith, J. E. \& Goodman, D. S. (1975). Journal of Lipid Research 16, 180-188.

Muhilal, H. \& Glover, J. (1974). British Journal of Nutrition 32, 549-558.

Nath, K. \& Olson, J. A. (1967). Journal of Nutrition 93, 461-469.

Neeld, J. B. \& Pearson, W. N. (1963). Journal of Nutrition 79, 454-462.

Sklan, D., Budowski, P., Ascarelli, I. \& Hurwitz, S. (1973). Journal of Nutrition 103, 1299-1305.

Sklan, D., Dahan, M., Budowski, P. \& Hurwitz, S. (1977). Journal of Nutrition 107, 1996-2001.

Sklan, D. \& Donoghue, S. (1982). Journal of Nutrition 112, 759-765.

Sklan, D., Dubrov, D., Eisner, U. \& Hurwitz, S. (1975a). Journal of Nutrition 105, 1549-1552.

Sklan, D., Hurwitz, S., Budowski, P. \& Ascarelli, I. (1975b). Journal of Nutrition 105, 57-63.

Smith, J. E. \& Goodman, D. S. (1979). Federation Proceedings 38, 60-65.

Sondergaard, E. (1972). Experientia 28, 773-774.

Varma, R. N. \& Beaton, G. H. (1972). Canadian Journal of Physiology and Pharmacology 50, 1026-1077. 